\title{
POTENTIAL DISTRIBUTION OF PERSIAN GAZELLE (GAZELLA SUBGUTTUROSA SUBGUTTUROSA) IN BAMOO NATIONAL PARK, SHIRAZ, IRAN: A PRESENCE-ONLY MODEL APPROACH
}

\author{
HASSANVAND, A. ${ }^{1}$ - RADNEZHAD, H. ${ }^{2 *}$ - MARTYNOVA-VAN KLEY, A. ${ }^{2}-$ LONI, A. $^{1}$ - SADEGHI, M. ${ }^{3}$ - \\ ZAREMANESH, $\mathrm{H}^{4}$ \\ ${ }^{1}$ Department of Biology, Payame Noor University \\ PO BOX 19395-3697, Tehran, Iran \\ ${ }^{2}$ Department of Biology, Stephen F. Austin State University \\ Nacogdoches, TX, USA \\ ${ }^{3}$ Department of of Environmental Science, Islamic Azad University \\ Isfahan (Khorasgan) Branch, Iran \\ ${ }^{4}$ Department of Agriculture, Payame Noor University \\ PO BOX 19395-3697, Tehran, Iran \\ *Corresponding author \\ e-mail: hradnezhad@yahoo.com \\ (Received 21 ${ }^{\text {st }}$ Jun 2017; accepted $23^{\text {rd }}$ Nov 2017)
}

\begin{abstract}
Using 30 Gazella subgutturosa subgutturosa presence-only data related to maximum entropy (Maxent) and ecological niche factor analysis (ENFA) models, but gained from field surveys, the present study was an attempt to assess how the Persian gazelle (subgutturosa) was distributed in Bamoo National Park located in Shiraz, Iran. While Maxent is thought to be predictive of satisfaction of environmental requirements, ENFA is considered as a tool for investigating the niche and habitat preferences of the species. All of the analyses by the models demonstrated the species distribution and the subgutturosa habitat. According to Maxent, vegetation, trough, and predator were witnessed to be most influential in the distribution, whereas ENFA revealed that elevation and vegetation were of highest value in terms of Gazella subgutturosa subgutturosa distribution. Interestingly enough, the predator variable was found to be highly contributing by Maxent but avoidable by ENFA. Also, the prediction level of the models turned out to be higher than chance occurrence under curve $(\mathrm{AUC})=0.5$.
\end{abstract}

Keywords: ENFA, Gazella subgutturosa subgutturosa, habitat distribution, habitat preferences, Maxent, presence-only data

\section{Introduction}

To date, the issue of species distribution has gained much importance. According to Rebelo and Jones (2010), to gain an accurate piece of knowledge about how a given species is distributed is an area of investigation which is of high interest as far as conservation management is concerned. A careful review of the related literature reveals that a multitude of techniques has been developed to predict species distribution (e.g. Hirzel et al., 2002; Phillips et al., 2006). These techniques are, as Rebelo and Jones (2010) asserted, based upon the description of data related to the species in the form of presence or absence data in a set of sampled locations. It is the presence/absence data that facilitates the process by which the distribution of the species is predicted through the techniques or models (e.g. Osborne and Tigar, 1992; Brito et al., 1999; Carroll et al., 1999). Presence data, as Hortal et al. (2005) argues, usually correspond to the true 
presence of the species, but absences could be due to an insufficient sampling effort. Hence, false absences, according to Palmer et al. (2003), are much more common than false presences, and therefore there is a need for removing such inaccurate data from distributional maps (Palmer et al., 2003) and to assure the reliability of absences (Anderson, 2003). Zaniewski et al. (2002) argued that modeling based on presenceabsence data is more likely to reflect the present natural distribution of a species (i.e. the realized niche), whereas presence-only methods are more likely to predict potential distributions, more closely resembling the fundamental niche.

The most frequently used and common techniques for assessing species distribution on the basis of occurrence-only records include kernel smoothing techniques, the Ecological-Niche Factor Analysis (ENFA) approach developed by Hirzel and Guisan (2002), and the Maximum entropy method (Maxent) introduced by Phillips et al. (2006). Interestingly enough, it has never been proven that any of these techniques outperforms its competitors. Zaniewski et al. (2002) comparatively evaluated the performance of General Additive Models and ENFA models and concluded that ENFA was a better candidate for detecting the potential distribution hot spots, especially if occurrence-only data was used. Jiménez-Valverde et al. (2008) argues that making a comparison between SDM models including potential and realized distribution ones could be a controversial issue.

According to a multitude of research studies, Maxent outperforms ENFA and GARP models (e.g. Phillips et al., 2006; Sérgio et al., 2007). Phillips et al. (2006) stated that the Maxent model yields better results even when it comes to small-size samples. Maxent, according to Phillips and Dudik (2008), is optimal for predicting within the realized niche, even though it should be used with caution when it is used to predict outside the realized distribution.

Rebelo and Jones (2010) assert that the results gained from their study support the use of presence-only modeling as an indispensable tool within any survey design as shown by the discovery of B. barbastellus populations outside of the previously known range, and ENFA seems to be more suited to determining a species' potential distribution. In contrast, Maxent is better suited to determining a species' realized distribution. It is more successful in predicting occurrence in previously unsurveyed areas and can be recommended as a technique for determining the conservative distribution for a species. Maxent modeling can aid biodiversity conservation, especially when it is obliged to develop survey plans or first assessments of a species' distribution.

In this study, we compared two presence-only modeling techniques, namely ecological niche factor analysis (ENFA) and maximum entropy (Maxent), in order to predict the Persian gazelle species' distribution. These techniques differ in their modeling approaches; Maxent is a complex technique for establishing a flexible relationship between the dependent and independent variables, and therefore it is theoretically more suited to predict the realized distribution of a species (the locations and range of environmental conditions in which a species actually lives). ENFA, on the other hand, is a presence-only method, but it reduces the shape of a species' response to an Eco-geographical Variable (EGV) to a normal distribution. The predictions it makes are generally closer to the potential distribution of a species (for a detailed discussion see Jiménez-Valverde et al., 2008).

The Persian gazelle (G. subgutturosa subgutturosa) is a sub-species of the goitered gazelle (G. subgutturosa) in the genus gazelle, family Bovidae and order Artiodactyla. This subspecies is distributed from eastern Turkey to Iran, Pakistan, Turkmenistan, and 
Central Asia (Kingswood and Blank, 1996). It is mow categorized as Vulnerable (VU) and if conservation efforts are not implemented for this species in the near future, this could change into the Extinction (EX) category (IUCN Red List, 2013).

Hence, the main objectives of this study were to: (i) investigate both modeling techniques in terms of their predictions and discrepancies; (ii) determine which environment factors are relevant for each model; and (iii) validate these modeling techniques by comparing predicted distributions with the results obtained from ground sampling.

\section{Materials and methods}

\section{Study area}

Bamoo National Park (BNP) covers an area of 46913 hectares and is located in the northeastern part of Shiraz, Iran $\left(52^{\circ} 29^{\prime}\right.$ to $52^{\circ} 56^{\prime} \mathrm{E}, 2^{\circ} 39^{\prime}$ to $29^{\circ} 50^{\prime} \mathrm{N}$ ) (see Fig. 1). This park has been under protection since 1962. This park is covered by Astragalus spp, annual grass, and Artemisia spp. It is also characterized by mountainous areas and plains. Its maximum elevation equal $2700 \mathrm{~m}$.

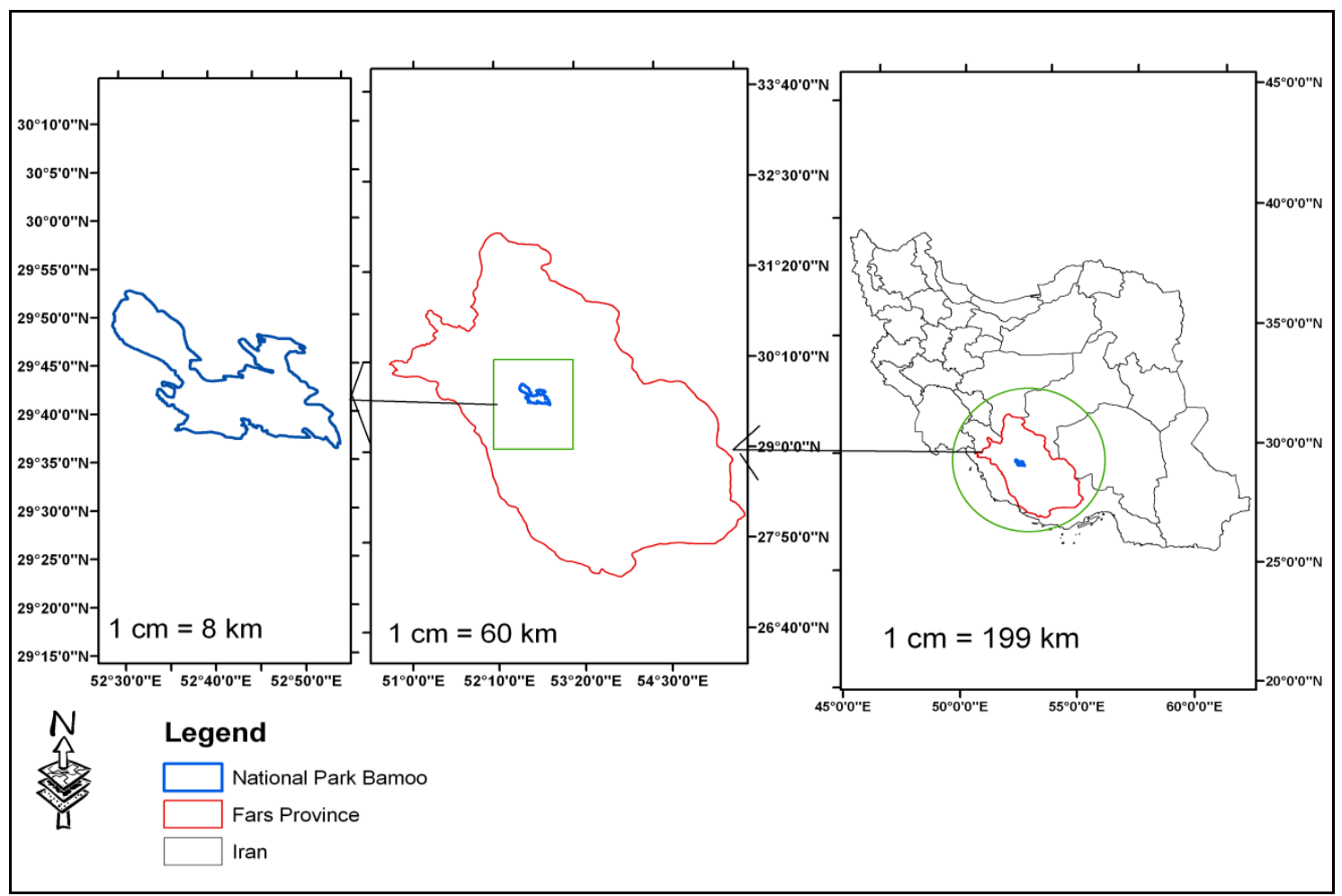

Figure 1. BNP geographical map

\section{Target species and occurrence data}

Thirty occurrence records of Gazella subgutturosa species collected in random systematic transect conducted in plain area of national park. Park ranger drive on line transect for $500(\mathrm{~m})$ and stop using binocular in 360 around to find out about the presence of Gazella. These data representing the total distribution of the species that are under severe threatening circumstances due to eco-geographical factors were obtained. 


\section{Environmental variables}

This study was based on such environmental variables as clouding, vegetation, trough, predator, soil structure, elevation, slope and road. As a potential predictor of the Gazella subgutturosa habitat distribution, a map of work layer (see Fig. 2) was also utilized.

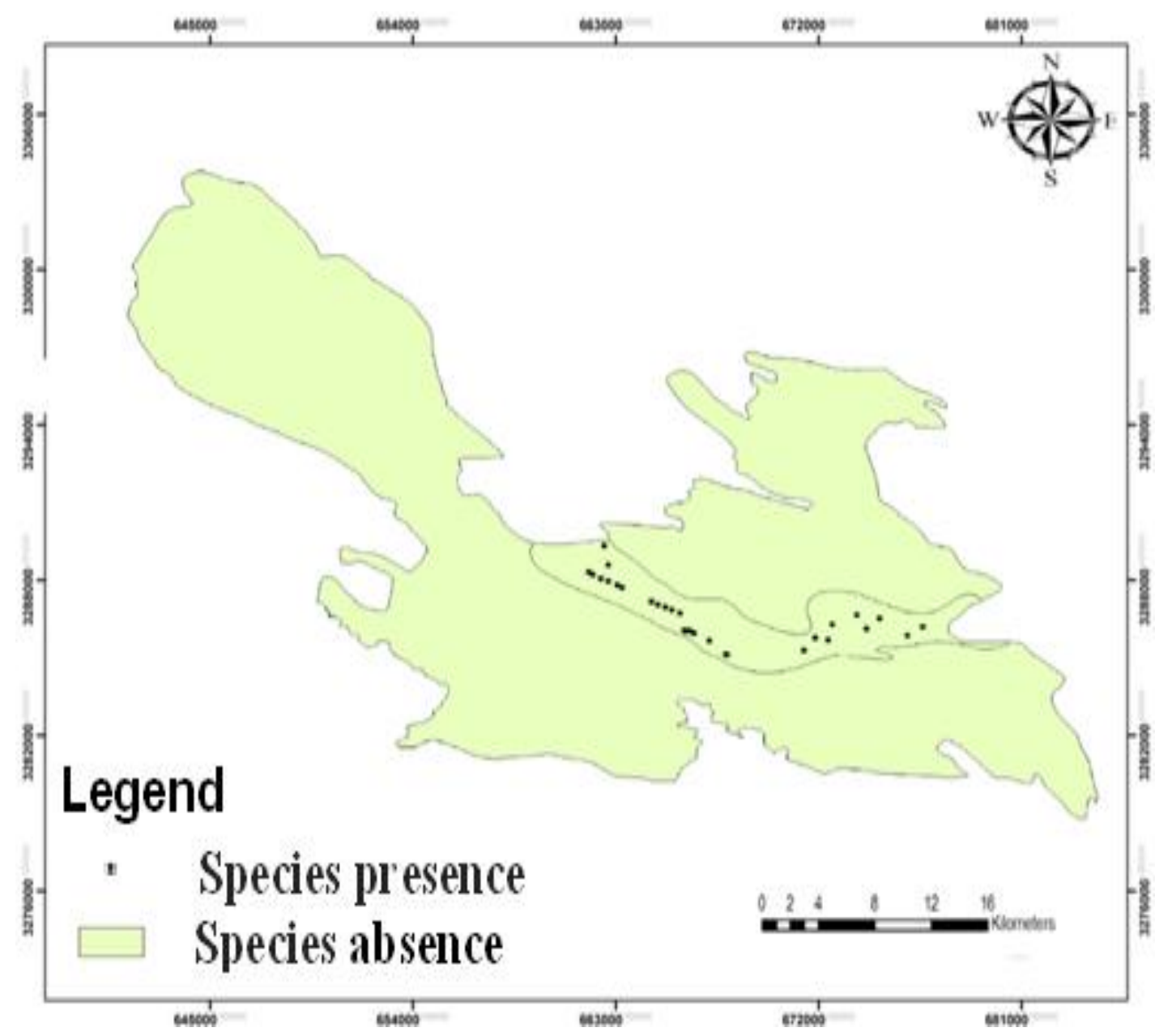

Figure 2. Map points (GPS) of the gazelle distribution in Bamoo National Park

These variables were chosen based on their biological relevance to animal species distributions and other habitat modeling studies (for example, $\mathrm{Hu}$ and Jiang, 2010; Bagherirad et al., 2010). Elevation (Digital Elevation Model; DEM) data were also obtained from the National Cartographic (IRNCC25K, $1 \mathrm{~km}$ spatial resolution). The DEM data were used to generate slope using Environmental Systems Research Institute's ARC GIS version 9.3. All environmental variables were resampled to $1 \mathrm{~km}$ spatial resolution. All the variables were tested for multicollinearity by examining the cross-correlations based on 30 localities species occurrence records as well as 30 randomly generated samples from the area. Only one variable from a set of highly cross-correlated variables ( $\mathrm{r}>0.75$ ) was included in the model based on the potential biological relevance to the distribution of the species and the ease of interpretation. 


\section{Modeling procedure}

\section{Maxent}

Maxent has been found to perform best among many different modeling methods (Elith et al., 2006; Ortega-Huerta and Peterson, 2008). It is based on a machine-learning program that estimates the probability distribution for a species' occurrence based on environmental constraints (Phillips et al., 2006). It requires only-presence data (not absence) and environmental variable (continuous or categorical) layers for the study area. We used the

freely available Maxent software (version 3.1 at http:// www.cs.princeton.edu/ schapire/maxent/) which generates an estimate of presence probability associated with the species. The 30 occurrence records and 7 environmental predictors were utilized to model the potential habitat distribution for Gazella subgutturosa. As previously mentioned, 30 independent data points were used to test the reliability level of the model using a binomial test of omission to evaluate the statistical significance of the prediction.

Also, the importance of each environmental variable was evaluated through a heuristic estimation during the model training as well as a jackknife test that was conducted by initially excluding one variable in each run, running the model with only one variable, and finally including all of the variables in the model (Fielding and Bell, 1997). Afterwards, the performance of each model was assessed, and the response curves were created for each environmental variable. This showed how each variable influenced the logistical prediction by keeping the remaining variables at their average value. It should be emphasized that to make a change in one of the variables included in the model had a marginal effect.

The model was evaluated in light of the threshold-independent receiver operating characteristic (ROC) approach by calculating the area under the ROC curve (AUC) as the measure of the prediction success (Hanley and McNeil, 1982). The ROC curve is obtained by plotting all true positive values (sensitivity fraction) against their equivalent false positive values (1-specificity fraction, Phillips et al., 2006). Analysis was performed 10 times to generate $95 \%$ confidence intervals.

\section{ENFA}

ENFA makes a comparison between the total area combinations of habitat variables available to the species and those of habitat variables at the locations where the species is found by means of two terms including marginality and specialization. Marginality is a measure of the separation between the optimal habitat combinations (those of the actual presence sites) and the average available environmental conditions within the study area (Liu et al., 2005).

Specialization contrasts the global distribution variance with the species habitat variance. It measures how restricted the species niche is in comparison with the habitat combinations available (Hirzel et al., 2002; Basille et al., 2008). ENFA is implemented in the Adehabitat package (Calenge, 2006) of $\mathrm{R}$ software (R Development Core Team, 2010). The analysis performs a principal component analysis by calculating the factors that have a biological meaning. Of the factors, the first one explains marginality $(\mathrm{m})$, but the remaining ones explain the specialization (s). Larger values of marginality indicate that the species is not equally distributed in the environment and that the habitats utilized strongly differ from the average conditions in the study area (Hirzel et al., 2002; Basille et al., 2008). Alternatively, small values of specialization represent less restricted niches on some particular environmental variable (Basille et al., 2008) and high values of specialization mean that the species do not 
tolerate variation in that dimension. Adehabitat package also provides global marginality (M) and global tolerance (T) of the species to the habitat evaluated: the greater the marginality, the more the niche deviates from the available conditions; the smaller the tolerance, the more restricted the niche is, i.e. more specialized is the species. These global estimations, however, must be used cautiously as they only apply to the specific area covered in a specific study and assume that the environmental variables do not change over time (Hirzel et al., 2002; Basille, per. comm). Marginality, the specialization axes and tolerance were evaluated with MonteCarlo tests to assess their significance after 999 replicates (Basille et al., 2008; 2009; Calenge and Basille, 2008). As in Maxent, the analysis was also evaluated by ROC approach. In order to perform this validation, ENFA was applied to a set of 200 random absence points created by Dismo package (Hijmans et al., 2010) of R software, avoiding land areas and areas nearby to presence points to minimize 'false' absences in these points. Then, the predicted suitability of both training and test data was contrasted with the ENFA results performed by the absence points by means of ROCR package (Sing et al., 2009) of R software.

\section{Results}

Given the results gained from the heuristic estimations of the Maxent model, the variables that make the most meaningful contribution to the model include vegetation (56\%), trough (18.4\%), and predator (12.1\%) (Table 1). The jackknife test presented by Figure 3 manifests that the variables mentioned above lead to the greatest results when considered in isolation, so they can be claimed to be more relevant for the Gazella subgutturosa distribution.

Table 1. Relative contributions of the environmental variables to Maxent and ENFA models

\begin{tabular}{|c|c|c|c|c|c|c|}
\hline \multirow{2}{*}{ Variable } & \multirow{2}{*}{$\begin{array}{c}\text { MAXENT } \\
\text { percent } \\
\text { contribution }\end{array}$} & $\begin{array}{c}\text { Marginality } \\
\mathbf{( 1 0 0 \% )}\end{array}$ & $\mathbf{S 2 ~ ( 1 4 . 3 \% )}$ & $\begin{array}{c}\mathbf{S 3} \\
\mathbf{7 1 . 1 8 \%} \mathbf{S 1}\end{array}$ & $\begin{array}{c}\text { S4 } \\
\mathbf{( 4 . 3 4 \% )}\end{array}$ & S5 (1\%) \\
\hline Vegetation & 56.6 & 0.476 & 0.345 & -0.123 & 0.043 & 0.067 \\
Trough & 18.4 & 0.637 & 0.354 & 0.316 & 0.105 & 0.185 \\
Predator & 12.1 & -0.372 & -0.248 & 0.031 & 0.041 & 0.059 \\
Soil structure & 2 & 0.326 & -0.223 & -0.128 & 0.063 & 0.196 \\
Elevation & 10.7 & 0.598 & 0.367 & 0.249 & 0.024 & -0.108 \\
Slope & 0.2 & 0.241 & 0.162 & 0.026 & -0.045 & 0.276 \\
Road & 0 & 0.243 & 0.126 & -0.141 & 0.043 & -0.063 \\
\hline
\end{tabular}

On the other hand, the variables that cause the highest amount of gain when they are omitted include the road, slope, elevation and soil structure. The Maxent model indicates that the predicted suitability of the Gazella subgutturosa increases in zones where the vegetation range is 9, 10 and 12 with such dominant species as Scariola orientalis, Astragalus gossypimus, Ebenus stellata, Achillea eriophora, Centaurea intricate, Ebernus stellata, Astragalus gossypimus, Astragalus rhodosemius, Stipa hohenackeriana, Helichrysum leucocephalum, Scariola orientalis, Astragalus fasciculifolius, Astragalus curviflorus, Astragalus cephalanthus and Astragalus susianus, Astragalus rhodosemius, Astragalus gossypinus, Astragalus cephalanthus, Astragalus fasciculifolius, Artemisia aucheri as well as the distance to trough, and 


$$
-311-
$$

distance to predator. Also, the elevation range associated with the classes is $0-<5000 \mathrm{~m}$, 5000-15000 m and 1600-1800 m, respectively (Fig. 4).

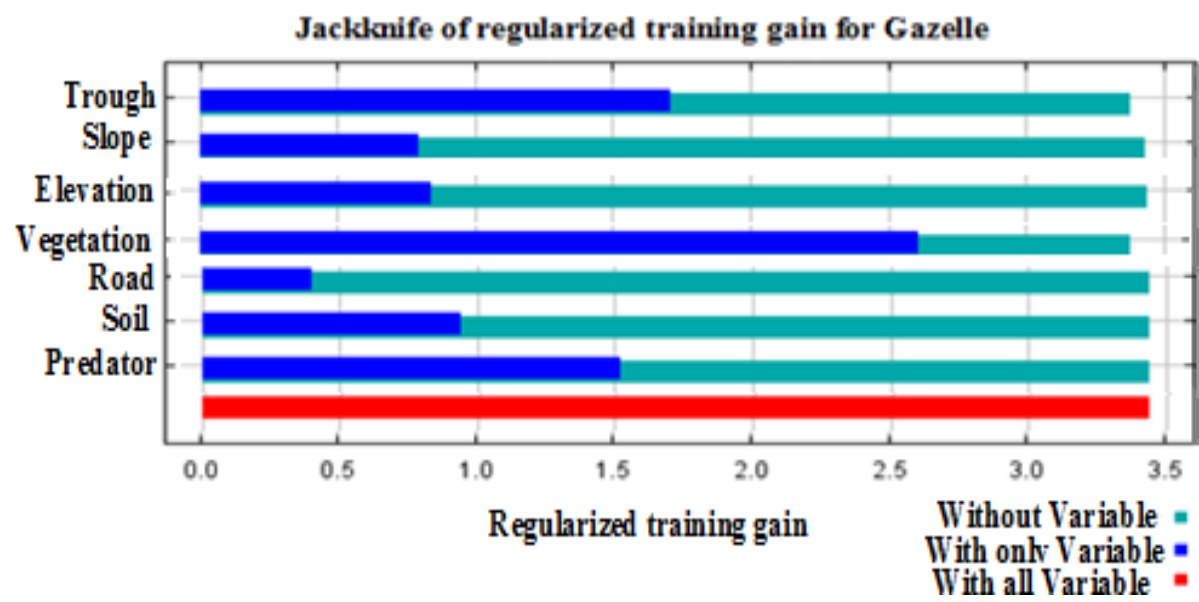

Figure 3. Results of the jackknife test of variable importance in the Maxent
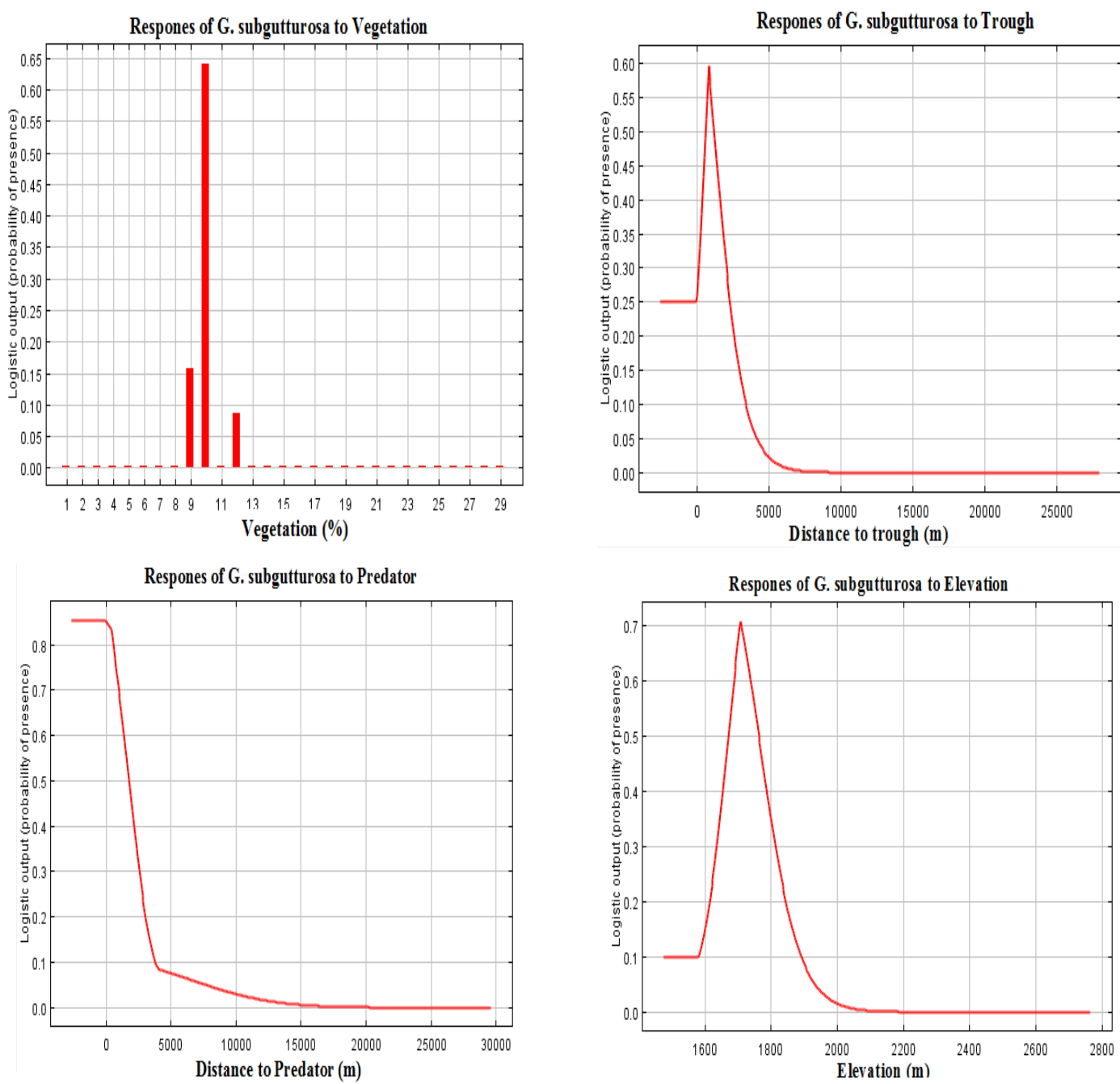

Figure 4. Response curves related to the most important variables of the Maxent model 
According to the model, the area under the curve (AUC) for the training data and the test data was 0.904 and 0.929 , respectively (Fig. 5). This means that the model prediction is higher than the chance $(\mathrm{AUC}=0.5)$. The map produced by the Maxent models is indicative of the areas having the best conditions for G. subgutturosa occurrence (Fig. 6), and it is congruent with the known distribution of G. subgutturosa (Fig. 2). In addition, several areas with higher probability of presence were identified in the marginal parts that are not yet under the influence of human activities.
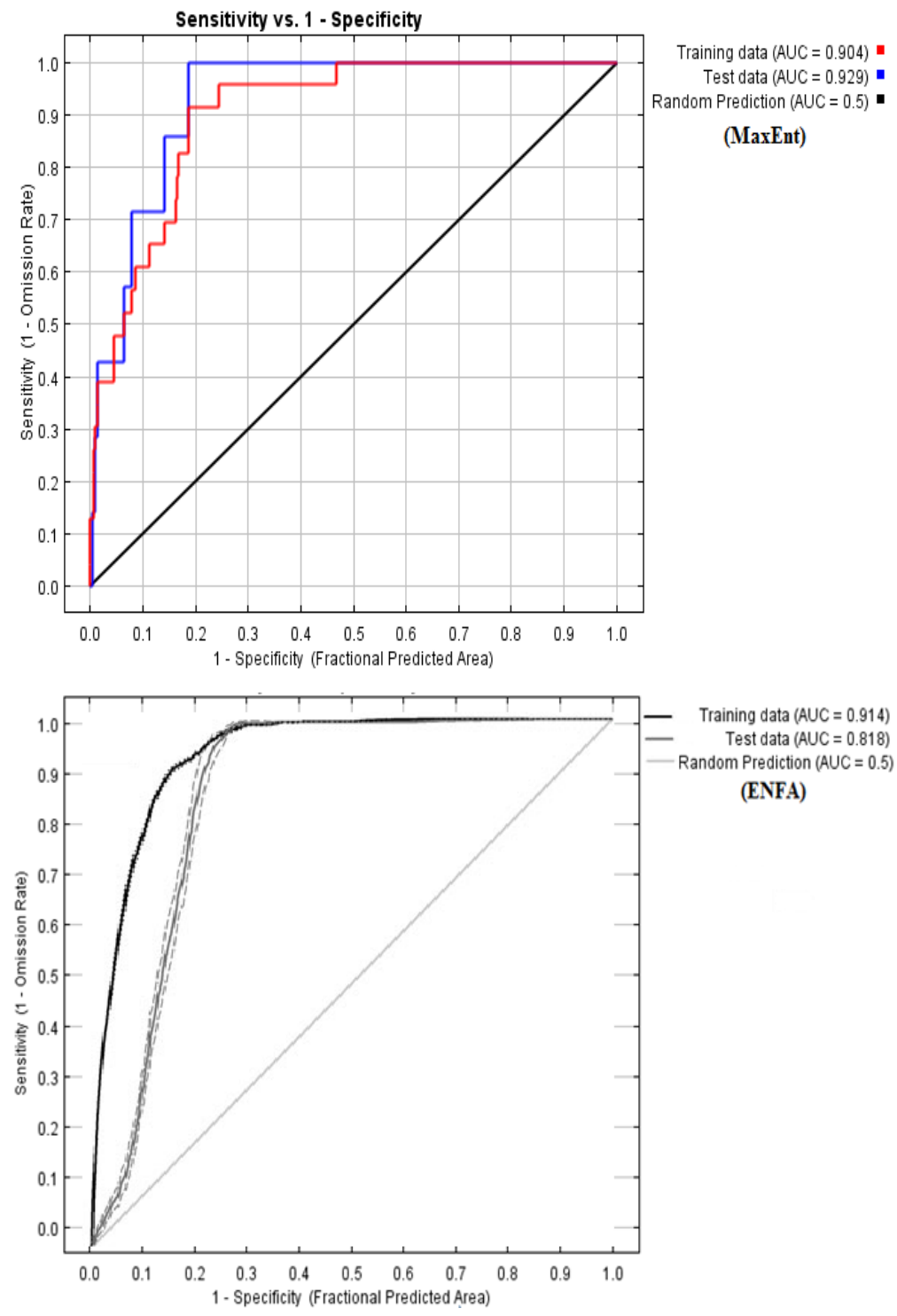

Figure 5. Receiver operating characteristic curve using Maxent and ENFA models

The global marginality estimated by ENFA was $1.35(\mathrm{P}=0.001)$. It indicates that the area used by Gazella subgutturosa differs from the average conditions in the Bamoo National Park (Table 1) niche centroid shown in (Fig. 7) and that it requires a specific habitat niche. As for the importance of the variables, the analysis indicates that trough, vegetation and elevation are the main variables that contribute to marginality (Table 1 and Fig. 7). 


$$
-313-
$$

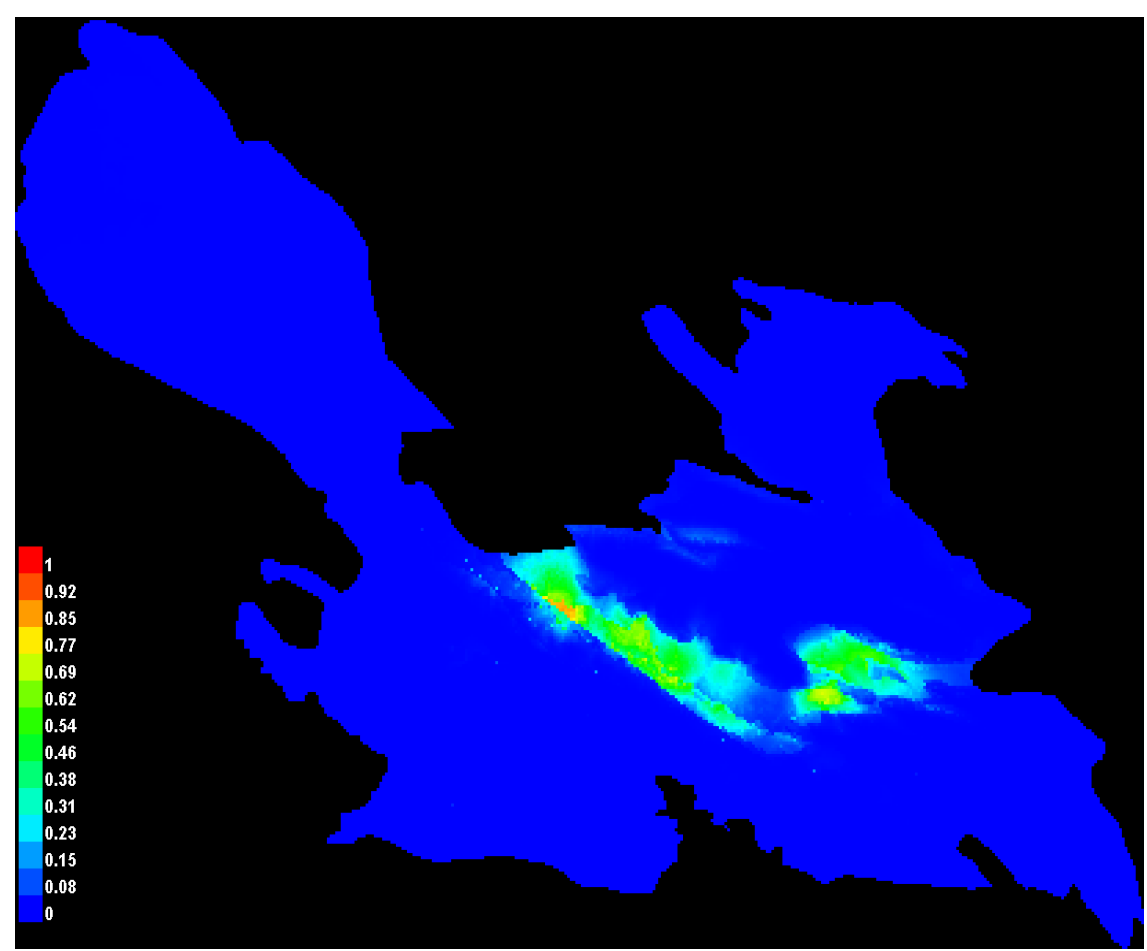

Figure 6. Distribution map by Maxent model

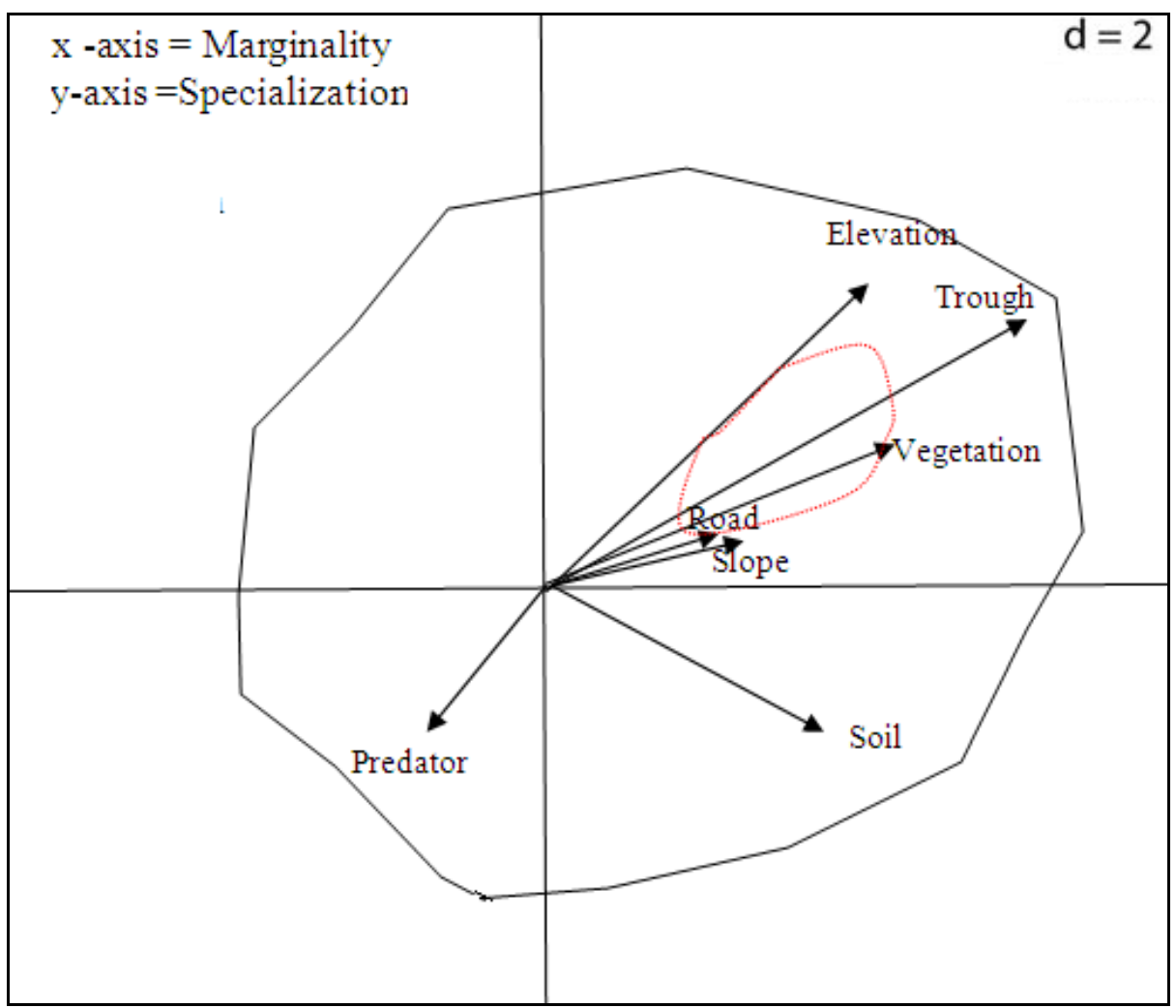

Figure 7. Ecological niche display of G. subgutturosa 
That trough, vegetation and elevation have large and positive values mean that Gazella subgutturosa prefers areas where these variables have an average greater than that of the environment (Fig. 7). Global specialization estimated by ENFA was $1.86(\mathrm{P}=0.001)$ indicating that Gazella subgutturosa is a specialized species which has a narrow field of ecology.

Trough and elevation are the variables that have higher specialization coefficients, thus they are most critical in terms of habitat selection (Fig. 7). The AUC related to the training and test data was 0.914 and 0.818, respectively (Fig. 5) meaning that the prediction of the model is also better than the randomness (AUC $=0.5)$, so the ability of the Maxent model to predict suitability areas is inferior to that of the ENFA model.

Habitat suitability maps obtained by ENFA were classified into classes, namely suitable habitat, intermediate habitat and unsuitable habitat (Fig. 8). It shows the areas with the best-predicted conditions for G. subgutturosa occurrence. Map obtained by the ecological niche factor analysis showed that the gazelles were observed mostly in areas with vegetation types include annual grasses, Astragalus spp, Artemisia sieberi, and other pasture species that have provided suitable habitats for this species. The unsuitable habitats are located in the southern area of the BNK. This was incompatible with the known distribution of G. subgutturosa (Fig. 2).

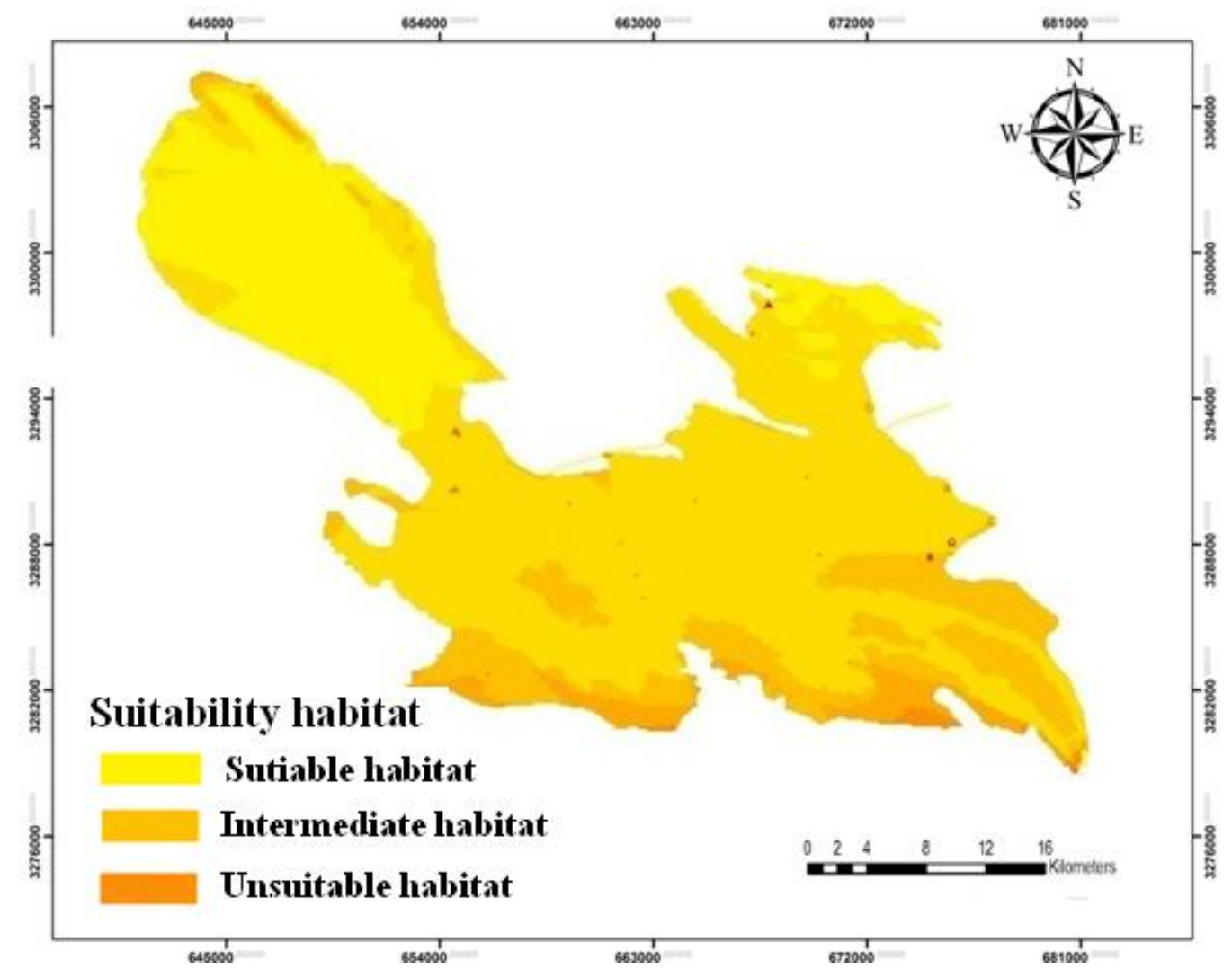

Figure 8. Habitat suitability map by ENFA model

As indicated by the figure above, the great polygons represent total available areas, but the small polygons represent used area (the niche centroid is located in the center of the small polygons). The arrows represent the projections of the environmental variables on the marginality and specialization axes. 


\section{Discussion}

Integrating multiple environmental variables and presence-only data, this study was an attempt to shed light on G. subgutturosa habitat preferences and distribution in the Bamoo National Park situated in Iran using such techniques as Maxent modeling and ENFA analysis. To date, some studies have been focused upon the local abundance of $G$. subgutturosa in light of presence-only data and ENFA model in relation to some environmental variables like elevation, slope, aspect, distance to road, distance to villages, distance to watercourse, distance to livestock herds, Normalized Difference Vegetation Index (NDVI), and predator (Bagherirad et al., 2014).

Maxent has achieved a robust performance showing a good accuracy with low sample sizes and an excellent predictive ability (Hernandez et al., 2006; Pearson et al., 2007; Wisz et al., 2008). The results gained from this study are in agreement with these studies, because, in terms of analysis comparison, ENFA model is more robust than Maxent as a predictive tool: both training and test AUC plots confirmed its high performance (Fig. 5). The test AUC of the Maxent had a lower value, although test data included the entire area that was incorporated in the training data. In contrast, ENFA had a lower fitness because the absence model was built using random points that covered most of the total available habitat, thus the model could not perform adequately. In addition, Maxent did not predict broad areas of distribution for the G. subgutturosa. Maxent proved to be robust at this scale which allowed the discovery of new populations and the extension of known distribution. In fact, Maxent and ENFA had different levels of success in predicting the occurrence of new populations.

Zaniewski et al., (2002) showed that ENFA produced accurate results although it had a tendency to overestimate the spatial extent of distributions, especially on the periphery of ranges (Brotons et al., 2004). Our results showed a similar pattern. A broad and accurate area of high-suitability was identified in the regions of BNK. ENFA was shown to be inaccurate in its predictions outside the geographical range of the training data.

It is important to understand why these two techniques yielded such different results in the discovery of new populations. Tsoar et al. (2007) concluded that more complex techniques (i.e. Maxent) are better predictors than the simple ones as they establish more flexible relationships between the dependent and independent variables. In fact, models that have no predefined shape of response curves can build models closer to the training data such as those based on smoothing techniques like Maxent (Randin et al., 2006). On the other hand, parametric methods like ENFA are limited by the normal distribution making them more sensitive to bias or extrapolations (Elith et al., 2006; Randin et al., 2006). Overall, Maxent seems prone to over fitting presence data (Peterson et al., 2007), so it is more likely to develop omission errors or false absences (the species exists in low suitability areas) while ENFA seemed to have greatest problems in reducing the commission error rate or false positives; it predicts occurrence where the species does not exist in areas outside the range of the training data. Both analyses agreed that trough, vegetation and elevation are variables relevant to $G$. subgutturosa spatial distribution and habitat preferences (Figs. 3 and 6), although they showed a small discrepancy in terms of the remaining variables. For instance, vegetation, trough, predator and elevation contribute most to the Maxent model (97.8\%), while the road and slope make a $0.2 \%$ contribution (Fig. 2). Gazelles are known to eat a variety of grasses, forbs, and shrubs during the different seasons (Olson et al., 2010; Xu et al., 2012). Persian gazelles feed mostly on Chenopodiacea, Gramineae, and forbs which are comprised of $38.8 \%$ to $85.1 \%$ (Karami et al., 2002; Wenxuan et al., 2008). In previous studies by Vallentine (2000) and 
Bagherirad et al. (2010), a positive relationship between these plant families and gazelles was observed. Although the Persian gazelles used all vegetation types, Types I and II were the most suitable habitats because of the higher density of annual forbs and grasses such as Astragalus spp, Bromus tectorum, Trigonella arcuata, and Eremopyrum bonaepartis and shrub species such as Artemisia herba-alba, Anabasis aphylla, Salsola rigida, and Aellenia sp. Vegetation type I in the low steppe area of the habitat was located at less than $1100 \mathrm{~m}$, but type II at 1100-1200 m elevation (Bagherirad et al., 2010). Using the Maxent model, Hu and Jiang (2010) showed that slope made a small contribution to the model development in terms of predicting the potential distribution of the endangered Przewalski's gazelle. Predator, on the other hand, made a significant contribution; However, it does seem to be a variable relevant (in terms of marginality and specialization) for the G. subgutturosa. These are reflections of the differences between both analyses. Although the ENFA model deals with spatial distribution, the Maxent counterpart focuses on habitat preferences. Therefore, in the former, a measurement of the distance to the predator is essential to the spatial distribution of the species, because the low distance of the predators is in direct relationship with high-risk areas of the $G$. subgutturosa. On the other hand, the predator is influential in its habitat preferences, which make sense because G. subgutturosa species should not select its habitat according to predator values. The results gained from this study are not suggestive of a major effect of the road on the G. subgutturosa distribution. In fact, the road was discarded during preliminary evaluations due to its low contribution to the analyses (Bagherirad et al., 2014). The ENFA analyses indicated a high marginality (1.40) and low tolerance (0.46) scores, suggesting a strong tendency for the species to live in a particular habitat throughout Golestan National Park as the context of the study. The interpretation of the factors in terms of its EGVs turned out to be very consistent with the experience of field specialists. In particular, the EGVs that correlated with the marginality factor were precisely those that were most often particularly relevant for the ecology of the gazelles.

The narrow distribution of the G. subgutturosa in the study area suggests that the species prefers a small range of environmental factors for their habitat confirmed by the high marginality and specialization factors. Recent studies about the interaction between human activities and the presence of the gazelle have shown that a negative relationship exists between the presence of the species and most types of human interference (Wangdwei and Fox, 2008; Hu et al., 2010; Ying et al., 2009; Ying et al., 2010; Bagherirad et al., 2014) whereas in our study the reverse was true. The road variable of the BNP with low marginality and specialization factors encompassed the main human activities and it was positively related to the occurrence of the G. subgutturosa. Previous studies have shown the effect of vegetation on G. subgutturosa habitat preferences, gazelles preferred an intermediate range of vegetation productivity, presumably facing quality-quantity trade-offs where areas with low NDVI are limited by low ingestion rates, and areas with high NDVI are limited by the low digestibility of mature forage (Mueller and Fagan, 2008).

\section{Conclusion}

In this study, we attempted to investigate the distribution of the species in the Bamoo National Park in order to develop a robust model based on environmental variables which are capable of predicting its distribution. Maxent and ENFA models helped identify habitat preferences and spatial distribution patterns of G. subgutturosa. Main 
environmental variables related to them are congruent with other life species in previous studies. To Maxent, vegetation, trough and predator are the variables most relevant to its spatial distribution; whereas to ENFA, trough, elevation and vegetation are the key variables in terms of habitat preferences. Also predator is a variable from which $G$. subgutturosa runs away. Maxent can successfully predict G. subgutturosa spatial distribution with the capability to evaluate which variables are more important to its distribution. This could be very useful in understanding the distributional patterns and geography of the species. In the future, this model can be applied in a wider geographical area to locate other habitable areas for G. subgutturosa, to add information about more or less suitable areas for the species and help elucidate the possible presence of the G. subgutturosa in regions where the actual identity of the species is uncertain.

\section{REFERENCES}

[1] Anderson, R. P. (2003): Real vs. artefactual absences in species distributions: test for Oryzomys albigularis (Rodentia Muridae) in Venezuela. - J. Biogeogr. 30: 591-605.

[2] Bagherirad, E., Ahmad, N., Amirkhani, M., Abdullah, M., Mesdaghi, M., Kabudi, A. (2014): Seasonal habitat use of Persian Gazelles (Gazella subgutturosa subgutturosa) based on vegetation parameters at Golestan National Park, Iran. - Arid Land Research and Management 28: 464-484.

[3] Bagherirad, E., Salmanmahiny, A, Norhayati, A., Maimon, A., Mesdaghi, M., Erfanian, B. (2010): Predicting habitat suitability of the goitered gazelle (Gazella subgutturosa subgutturosa) using presence-only data in Golestan National Park, Iran. - International Journal of Biological Sciences and Applications 1(4): 124-136.

[4] Basille, M., Calenge, C., Marboutin, E., Andersen, R., Gaillard, J. M. (2008): Assessing habitat selection using multivariate statistics: some refinements of the ecologicalniche factor analysis. - Ecological Modelling 211: 233-240.

[5] Basille, M., Herfindal, I., Santin-Janin, H., Linnell, J. D. C., Odden, J., Andersen, R., Høgda, K. A., Gaillard, J.-M. (2009): What shapes Eurasian lynx distribution in human dominated landscapes: selecting prey or avoiding people? - Ecography 32: 683-691.

[6] Brito, J. C., Crespo, E. G., Paulo, O. S. (1999): Modelling wildlife distributions: Logistic multiple regression vs overlap analysis. - Ecography 22: 251-260.

[7] Brotons, L., Thuiller, W., Araújo, M. B., Hirzel, A. H. (2004): Presence-absence versus presence-only modelling methods for predicting bird habitat suitability. - Ecography 27: 437-448.

[8] Calenge, C. (2006): The package adehabitat for the R software: a tool for the analysis of space and habitat use by animals. - Ecological Modelling 197: 516-519.

[9] Calenge, C., Basille, M. (2008): A general framework for the statistical exploration of the ecological niche. - Journal of Theoretical Biology 252: 674-685.

[10] Carroll, C., Zielinski, W. J., Noss, R. F. (1999): Using presence-absence data to build and test spatial habitat models for the fisher in the Klamath Region, USA. - Conserv. Biol. 13: $1344-1359$.

[11] Development Core Team, R. (2010): R: a language and environment for statistical computing. - R Foundation for Statistical Computing, Vienna. ISBN 3-900051-07-0. http://www.R-project.org.

[12] Elith, J., Graham, C. H., Anderson, R. P., Dudik, M., Ferrier, S., Guisan, A., Hijmans, R. J., Huettmann, F., Leathwick, J. R., Lehmann, A., Li, J., Lohmann, L. G., Loiselle, B. A., Manion, G., Moritz, C., Nakamura, M., Nakazawa, Y., Overton, J. M., Peterson, A. T., Phillips, S. J., Richardson, K., Scachetti-Pereira, R., Schapire, R. E., Soberon, J., Williams, S., Wisz, M. S., Zimmermann, N. E. (2006): Novel methods improve prediction of species' distributions from occurrence data. - Ecography 29: 129-151. 
[13] Fielding, A. H., Bell, J. F. (1997): A review of methods for the assessment of prediction errors in conservation presence/absence models. - Environmental Conservation 24: 38-49.

[14] Hanley, J. A., McNeil, B. J. (1982): The meaning and use of the area under a Receiver Operating Characteristic (ROC) curve. - Radiology 143: 29-36.

[15] Hernandez, P. A., Graham, C. H., Master, L. L., Albert, D. L. (2006): The effect of sample size and species characteristics on performance of different species distribution modeling methods. - Ecography 29: 773-785.

[16] Hijmans, R., Phillips, S. Leathwick, J., Elith, J. (2010): Dismo: Species distribution modeling. R package version 0.5-4. - http://CRAN.R-project.org/ package=dismo.

[17] Hirzel, A. H., Guisan, A. (2002): Which is the optimal sampling strategy for habitat suitability modelling. - Ecological Modelling 157(2-3): 331-341.

[18] Hirzel, A., Hausser, J., Chessel, D., Perrin, N. (2002): Ecological-niche factor analysis: how to compute habitat-suitability maps without absence data? - Ecology 83(7): 20272036.

[19] Hortal, J., Borges, P. A. V., Dinis, F., Jiménez-Valverde, A., Chefaoui, R. M., Lobo, J. M., Jarroca, S., Brito de Azevedo, E., Rodrigues, C., Madruga, J., Pinheiro, J., Gabriel, R., Cota Rodrigues, F., Pereira, A. R. (2005): Using ATLANTIS-Tierra 2.0 and GIS Environmental Information to Predict the Spatial Distribution and Habitat Suitability of Endemic Species. - In: Borges, P. A. V., Cunha, R., Gabriel, R., Martins, A. F., Silva, L., Vieira, V. (eds.) A List of the Terrestrial Fauna (Mollusca and Arthropoda) and Flora (Bryophyta, Pteridophyta and Spermatophyta) from the Azores. Direcção Regional do Ambiente and Universidade dos Açores, Horta, Angra do Heroísmo and Ponta Delgada.

[20] Hu, J., Jiang, Z. (2010): Predicting the potential distribution of the endangered Przewalski's gazelle. - Journal of Zoology 282: 54-63.

[21] Hu, J., Ping, X., Cai, J., Li, Z., Li, C., Jiang, Z. (2010): Do local communities support the conservation of endangered Przewalski's Gazelle? - European Journal of Wildlife Research 56(4): 551-560.

[22] IUCN Red List (2013): http://www.iucnredlist.org. - Last accessed 17 March 2014.

[23] Jiménez-Valverde, A., Lobo, J. M., Hortal, J. (2008): Not as good as they seem: the importance of concepts in species distribution modelling. - Diversity and Distributions 14(6): 885-890.

[24] Karami, M., Hemami, M. R., Groves, C. P. (2002): Taxonomic, distributional and ecological data on gazelles in Iran. - Zoology in the Middle East 26(1): 29-36.

[25] Kingswood, S. C., Blank, D. A. (1996): Gazella subgutturosa. - Mammalian Species 518: $1-10$.

[26] Liu, C., Berry, P. M., Dawson, T. P., Pearson, R. G. (2005): Selecting thresholds of occurrence in the prediction of species distributions. - Ecography 28: 385-393.

[27] Mueller, T. M., Fagan, W. F. (2008): Search and navigation in dynamic environments from individual behaviors to population distributions. - Oikos 117: 654-664.

[28] Olson, K. A., Murray, M. G., Fuller, T. K. (2010): Vegetation composition and nutritional quality of forage for gazelles in Eastern Mongolia. - Rangeland Ecology and Management 63(5): 593-598.

[29] Ortega-Huerta, M. A., Peterson, A. T. (2008): Modeling ecological niches and predicting geographic distributions: a test of six presence-only methods. - Revista Mexicana De Biodiversidad 79: 205-216.

[30] Osborne, P. E., Tigar, B. J. (1992): Interpreting bird atlas using logistic models: an example from Lesotho, Southern Africa. - J. Appl. Ecol. 29: 55-62.

[31] Palmer, M., Gómez-Pujol, L., Pons, G. X., Mateu, J., Linde, M. (2003): Noisy data and distribution maps: the example of Phylan semicostatus Mulsant and Rey, 1854 (Coleoptera, Tenebrionidae) from Serra de Tramuntana (Mallorca, Western Mediterranean). - Graellsia 59: 389-398. 
[32] Pearson, R. G., Raxworthy, C. J., Nakamura, M., Peterson, A. T. (2007): Predicting species distributions from small numbers of occurrence records: a test case using cryptic geckos in Madagascar. - J. Biogeo. 34: 102-117.

[33] Peterson, A. T., Papes, M., Eaton, M. (2007): Transferability and model evaluation in ecological niche modeling: a comparison of GARP and Maxent. - Ecography 30: 550560.

[34] Phillips, S. J., Anderson, R. P., Schapire, R. E. (2006): Maximum entropy modeling of species geographic distributions. - Ecological Modelling 190(3-4): 231-259.

[35] Phillips, S. J., Dudik, M. (2008): Modeling of species distributions with Maxent: new extensions and a comprehensive evaluation. - Ecography 31(2): 161-175.

[36] Randin, C. F., Dirnböck, T., Dullinger, S., Zimmermann, N. E., Zappa, M. Guisan, A. (2006): Are niche-based species distribution models transferable in space? - Journal of Biogeography 33: 1689-1703.

[37] Rebelo, H., Jones, G. (2010): Ground validation of presence-only modelling with rare species: a case study on barbastelles Barbastella barbastellus (Chiroptera: Vespertilionidae). - Journal of Applied Ecology 47(2): 410-420. doi: 10.1111/j.13652664.2009.01765.x.

[38] Sérgio, C., Figueira, R., Draper, D., Menezes, R., Sousa, A. J. (2007): Modelling bryophyte distribution based on ecological information for extent of occurrence assessment. - Biological Conservation 135 (3): 341-351.

[39] Sing, T., Sander, O., Beerenwinkel, N., Lengauer, T. (2009): ROCR: Visualizing the performance of scoring classifiers. $\mathrm{R}$ package version 1.0-4. - http://CRAN.Rproject.org/package=ROCR.

[40] Tsoar, A., Allouche, O., Steinitz, O., Rotem, D., Kadmon, R. (2007): A comparative evaluation of presence-only methods for modelling species distribution. - Diversity and Distributions 13: 397-405.

[41] Wangdwei, M., Fox, J. L. (2008): Habitat selection by sympatric Chiru and Tibetan Gazelle in the Aru Basin, Chang Tang Nature Reserve, Tibet Autonomous Region, China. - Acta Theriologica Sinica 28(3): 225-231.

[42] Wenxuan, X. U., Jianfang, Q., Wei, L., Weikang, Y. (2008): Food habits of goitered gazelles (Gazella Subgutturosa Sairensis) in Northern Xinjiang (in Chinese). - Acta Theriologica Sinica 28(3): 280-286.

[43] Wisz, M. S., Hijmans, R. J., Li, J., Peterson, A. T., Graham, C. H., Guisan, A., NCEAS Predicting Species Distributions Working Group (2008): Effects of sample size on the performance of species distribution models. - Diversity and Distributions 14: 763-773.

[44] Xu, W., Xia, C., Lin, J., Yang, W., Blank, D. A., Qiao, J., Liu, W. (2012): Diet of Gazella subgutturosa (Güldenstaedt, 1780) and food overlap with domestic sheep in Xinjiang, China. - Folia Zool. 61(1): 54-60.

[45] Ying, L., Wenxuan, X., Jian-Fang, Q., Wei-Kang, Y. (2009): Spatio-temporal distribution and habitat selection of Gazella Subgutturosa in Kalamaili Mountain Nature Reserve in four seasons. - Arid Land Geography 32(2): 261-267.

[46] Ying, L., Wenxuan, X., Weikang, Y., Jiangfang, Q., Wei, L., Canjun, X. (2010): Habitat suitability assessment of Gazella Subgutturosa in Kalamaili Mountain Nature Reserve. Acta Theriologica Sinica 30(1): 11-20.

[47] Zaniewski, A. E., Lehmann, A., Overton, J. M. (2002): Predicting species spatial distributions using presence-only data: a case study of native New Zealand ferns. - Ecol. Model. 157: 261-280. 